\title{
Long-term and spillover effects of a marine protected area on an exploited fish community
}

\author{
Ben Stobart ${ }^{1, *}$, Richard Warwick ${ }^{2}$, César González ${ }^{1}$, Sandra Mallol ${ }^{1}$, David Díaz ${ }^{1}$, \\ Olga Reñones ${ }^{1}$, Raquel Goñi ${ }^{1}$
}

\author{
${ }^{1}$ Instituto Español de Oceanografía, Centro Oceanográfico de Baleares, Palma de Mallorca 07015, Spain
}

${ }^{2}$ Plymouth Marine Laboratory, Plymouth PL1 3DH, UK

\begin{abstract}
We assessed the development of the exploited fish community inside and around the Columbretes Islands Marine Reserve (CIMR), a marine protected area (MPA), 8 to 16 yr after fishing ceased in the reserve. Sampling was by annual lobster trammel net fishing, an experimental technique used inside the CIMR, and on-board commercial operations in adjacent fishing grounds. We examined trends in combined fish abundance and biomass (catch per unit effort), species richness and diversity, size structure, trophic level and species composition of the community. Our results showed the CIMR fish community continued to change throughout the study period as (1) abundance and biomass increased, (2) mean body size and trophic level increased and (3) species composition changed according to a linear model. Relative to nearby fished areas the CIMR fish community had (1) higher abundance and biomass, (2) lower species diversity and higher taxonomic distinctness, (3) larger relative body size and (4) no difference in mean trophic level. We found clear evidence of spillover of fish from the CIMR to the adjacent fishery as commercial fish yields at the MPA border ( $<0.5 \mathrm{~km}$ from the boundary) increased continuously during the study period, despite being locally depleted due to fishing effort concentration (fishing the line). Furthermore, fish size and diversity at the border were intermediate between the CIMR and other fished zones, suggesting that this is a transitional zone influenced by this MPA. Our results show that changes in community abundance, biomass, size structure and species composition provide a clear and interpretable view of MPA recovery. Diversity indices are also useful; however, their interpretation is more difficult. We conclude that the creation of the CIMR has had a positive effect on the exploitable fish community and that there is evidence of exportation of biomass to the surrounding fishery. We highlight the advantage of using multiple community metrics to study changes in fish communities, yet recommend the need for caution when interpreting them.
\end{abstract}

KEY WORDS: Marine protected area $\cdot$ Fish community development $\cdot$ Spillover $\cdot$ Biomass $\cdot$ Diversity Size spectra $\cdot$ Trophic level $\cdot$ Artisanal fishery $\cdot$ Mediterranean Sea

\section{INTRODUCTION}

Sustained exploitation of marine organisms has led to the depletion of populations of target species throughout the world (FAO 2007). One of the ecological costs of fishing is the incidental catch of organisms not targeted by the fisheries. In this context, artisanal fisheries are generally perceived as highly efficient low impact fisheries that generate few discards (e.g. Borges et al. 2001, Mas et al. 2004). However, despite having preferred target species Mediterranean artisanal fisheries are multispecific and affect numerous species (Colloca et al. 2004, Goñi et al. 2008). Trammel nets are among the most important gears that artisanal fishers use in the Mediterranean Sea (e.g. Goñi et al. 2008). While trammel nets are often target specific, an important part of the catch consists of multi-species bycatch (Stergiou et al. 2006), as occurs in the spiny lobster Palinurus elephas trammel net fishery that operates throughout the western Mediterranean Sea 
(Goñi \& Latrouite 2005). The commercial bycatch of the western Mediterranean lobster fishery is made up of up to 87 commercial species of finfish, molluscs and crustaceans that are increasingly relied upon to supplement dwindling lobster yields (Quetglas et al. 2004). About $54 \%$ of the catch in number (excluding non-commercial benthos such as bryozoans, sponges, algae and echinoderms) are commercialised fishes of high value such as largescale scorpionfish Scorpaena scrofa, anglers Lophius spp., john dory Zeus faber and great forkbeard Phycis phycis.

Marine protected areas (MPAs) have become a popular management tool in the Mediterranean Sea with the last census reporting 66 operational areas in the western Mediterranean (Ramos-Esplá et al. 2004). Expected benefits of MPAs to fishes in this region include an increase in abundance, biomass and fecundity, as well as a potential for benefits to biodiversity (García-Charton et al. 2008). Indeed, high exploitation rates and limited mobility of species targeted by artisanal fisheries have resulted in rapid biomass build up inside western Mediterranean MPAs (Sánchez-Lizaso et al. 2000). The Columbretes Islands Marine Reserve (CIMR), was created in 1990 to, amongst broader fishery and conservation objectives, protect traditional Palinurus elephas fishing grounds. At that time all professional fishing was banned in the CIMR, though recreational fishing continued until 2002 when anchoring was prohibited and essentially drew closure on this activity. Studies conducted in the CIMR to assess its effectiveness on the lobster population, 7 to $12 \mathrm{yr}$ after this MPA was established, showed that abundance and reproductive potential within the reserve was greater than in comparable fished areas (Goñi et al. 2001, 2003a), and that spillover of lobsters from the CIMR increased catches in the adjacent commercial fishery up to $1.5 \mathrm{~km}$ from its boundaries (Goñi et al. 2006). The CIMR also protects a diverse fish population, which in 1996, 6 yrs after protection was initiated, showed higher abundance and biomass than in equivalent fished areas (García-Charton et al. 2004). A study conducted between 1998 and 2000 on Scorpaena scrofa in the CIMR also showed that within the protected area individuals of this species were larger and more abundant (Reñones et al. 2001).

Most multispecies studies of MPA effects in the Mediterranean Sea have targeted shallow littoral fish communities assessed by underwater visual census (e.g. García-Charton et al. 2004, Harmelin-Vivien et al. 2008), while few studies have assessed the temporal changes of exploited communities in deep water using other methods (e.g. Goñi et al. 2001, Reñones et al. 2001). In this study we assess the development of the fish assemblage (hereafter 'community') exploited by the spiny lobster trammel net fishery 8 to 16 yr (1998 to
2006) after it was banned in 1990 in the CIMR. The distinctive characteristics of that community in the CIMR and in the nearby fished grounds at increasing distances from the CIMR are also explored. We have assumed that fishing effort in the nearby lobster fishery has remained constant during the study period (R. Goñi unpubl. data) and are certain that the fishing prohibition is well enforced in the CIMR. Therefore, we expect that abundance and biomass of fish species with high catchability in lobster trammel nets should follow increasing trends inside the CIMR while they should remain stable at lower levels in fished areas. Consequently we have hypothesized that (1) protection in the CIMR will mostly result in positive changes at the community level over time, (2) the fish community protected from lobster trammel net fishing in the CIMR will be different from that in comparable, nearby fished areas and (3) this difference will increase with distance from the CIMR boundary (or that, due to 'spillover' effects, the community in the fished areas closest to the CIMR will resemble the CIMR more than those farther away). To assess the change of the exploited fish community in the CIMR we examined trends in (1) total species abundance and biomass, (2) species richness and diversity, (3) community size structure and mean trophic level and (4) species composition. These variables were also used to compare the fish community in the CIMR with those in exploited areas at increasing distances from the CIMR boundary. Because the effects on diversity remain unclear, we have used a suite of indices to assess this response to fishing (Rochet \& Trenkel 2003).

\section{MATERIALS AND METHODS}

Study site. This study took place in the CIMR and surrounding fishing grounds (Fig. 1). The CIMR is located $50 \mathrm{~km}$ east from the Mediterranean coast of Spain and protects $44 \mathrm{~km}^{2}$ of volcanic rock and coralligenous habitats (maërl beds) with patches of gravel, sand and mud that extend down to depths of $80 \mathrm{~m}$. Fishing grounds near the CIMR consist of patches of rock and maërl over expanses of gravel, sand and mud predominantly at depths of 60 to $100 \mathrm{~m}$. The CIMR was a traditional lobster fishing ground before it was closed to fishing in 1990. Since then, fishing effort in the region has been concentrated along the CIMR boundaries and in nearby fishing grounds $(<30 \mathrm{~km}$ from the CIMR) and the number of boats participating in the local lobster fishery has declined, while fishing effort per boat has steadily increased. During the study period, no more than 6 artisanal boats fished consistently in the area. There is also frequent bottom trawling near the CIMR although both fisheries rarely over- 
lap. The MPA legislation prohibits all fishing except very limited recreational (prior to 2002 recreational fishing was allowed) and commercial fishing (pelagic species), which essentially renders the entire CIMR a 'no take zone'. Fishing regulations in the CIMR are well enforced by a permanent ranger staff.

Data collection. CIMR: Data were collected in experimental fishing surveys conducted annually between June and September inside the CIMR as part of a monitoring programme started in 1998. The surveys were carried out with one of the commercial boats that operate in the area, and with the same gear type used in the commercial fishery. A detailed description of the survey method is given in Goñi et al. (2003b). Surveys available for this study were for the 1998 to 2006 period and followed a standardized depthstratified sampling design with approximately 9 randomly placed fishing sets in each of 2 depth strata: shallow (25 to $50 \mathrm{~m}$ ) and deep (50 to $80 \mathrm{~m}$ ). In total 163 fishing sets were available to study the development of the exploited community in the CIMR.

Fished areas: Fishery data were collected by means of sampling on board commercial lobster boats operating around the CIMR from 1998 to 2006 (except 2004) during the 6 mo (March to August) lobster fishing season. Whenever possible, sampling took place during 1 wk per month on board one of the boats that fished more consistently in the region. The observer sampled all the fishing sets that were carried out in that week without directing where fishing sets should be allocated. In this fishery, trammel nets (gear description in Goñi et al. 2003b) are set over rocky and coralligenous habitats and left in place (soaked) for several days (mean 4 to $5 \mathrm{~d}$ ) depending on weather conditions. Over the study period 349 commercial fishing sets were sampled within $27 \mathrm{~km}$ of the CIMR boundary at depths of 50 to $100 \mathrm{~m}$.

In all the commercial and experimental fishing operations, data on net length, soak time, fishing location and depth along with catch by species and individual size of all fish were recorded. All commercial species of fish caught, with the exception of pelagic species caught accidentally, were used in the analyses. Data for this study included 51 commercial fish species belonging to 20 families (Table 1).

Study design. Community development within the CIMR: To study the development of the fish community in the CIMR we used data collected in experimental surveys during the study period over the whole depth range (20 to $80 \mathrm{~m}$ ) of the CIMR.

Spatial comparison of protected versus exploited communities: For the purpose of comparing the fish community protected in the CIMR with those in the nearby exploited areas, we grouped the data into 4 spatial categories (zones) according to distance from each fishing set to the CIMR as follows: (1) within the CIMR, (2) fishing grounds bordering the CIMR within $0.5 \mathrm{~km}$ from its boundary or 'border grounds' (BOR), (3) fishing grounds located from 0.5 to $5 \mathrm{~km}$ from the

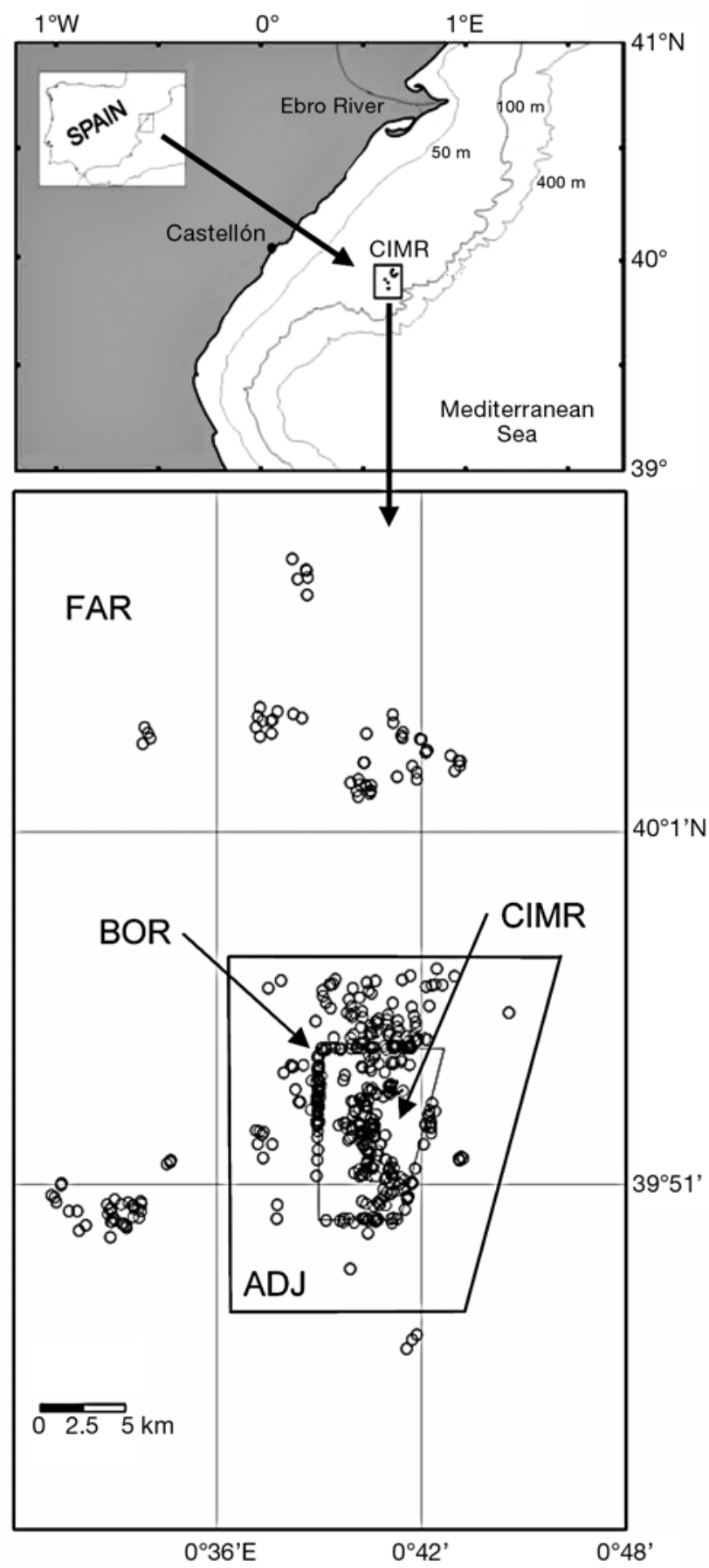

Fig. 1. The western Mediterranean Sea with the location of the Columbretes Islands Marine Reserve (CIMR) and surrounding fishing grounds showing the position of the fishing sets and zone designation. FAR: far grounds; BOR: border grounds; ADJ: adjacent grounds 
Table 1. Species and mean abundance (catch per unit effort numbers, NCPUE, in no. fish per $600 \mathrm{~m}$ net) making up the fish community studied inside the Columbretes Islands Marine Reserve (CIMR) ( $\mathrm{n}=163$ fishing sets) and the nearby fishery area (grouped as border, adjacent and far fished grounds, $\mathrm{n}=349$ fishing sets). - : no fish caught

\begin{tabular}{|c|c|c|c|}
\hline \multirow[t]{2}{*}{ Family } & \multirow[t]{2}{*}{ Species } & \multicolumn{2}{|c|}{ NCPUE } \\
\hline & & CIMR & $\begin{array}{c}\text { Fished } \\
\text { zones }\end{array}$ \\
\hline Scorpaenidae & Scorpaena scrofa & 4.006 & 1.413 \\
\hline Rajidae & Raja montagui & 2.809 & 0.164 \\
\hline Phycidae & Phycis phycis & 1.145 & 0.466 \\
\hline Zeidae & Zeus faber & 1.079 & 0.568 \\
\hline Sciaenidae & Sciaena umbra & 0.712 & 0.251 \\
\hline Sparidae & Dentex dentex & 0.461 & 0.103 \\
\hline Scyliorhinidae & Scyliorhinus stellaris & 0.455 & 0.061 \\
\hline Rajidae & Raja polystigma & 0.400 & 0.000 \\
\hline Lophiidae & Lophius piscatorius & 0.361 & 0.728 \\
\hline Rajidae & Raja brachyura & 0.326 & - \\
\hline Sparidae & Spondyliosoma cantharus & 0.291 & 0.103 \\
\hline Sparidae & Pagellus acarne & 0.227 & 0.224 \\
\hline Sparidae & Pagellus erythrinus & 0.221 & 0.276 \\
\hline Torpedinidae & Torpedo marmorata & 0.220 & 0.133 \\
\hline Sparidae & Pagrus pagrus & 0.200 & 0.080 \\
\hline Lophiidae & Lophius budegassa & 0.137 & 0.291 \\
\hline Uranoscopidae & Uranoscopus scaber & 0.108 & 0.116 \\
\hline Serranidae & Epinephelus marginatus & 0.052 & 0.012 \\
\hline Carangidae & Trachurus picturatus & 0.050 & 0.015 \\
\hline Scyliorhinidae & Scyliorhinus canicula & 0.041 & 0.110 \\
\hline Trachinidae & Trachinus radiatus & 0.037 & 0.009 \\
\hline Triglidae & Trigloporus lastoviza & 0.027 & 0.009 \\
\hline Congridae & Conger conger & 0.021 & 0.020 \\
\hline Labridae & Labrus bimaculatus & 0.020 & 0.018 \\
\hline Labridae & Labrus merula & 0.020 & - \\
\hline Scorpaenidae & Scorpaena porcus & 0.018 & 0.003 \\
\hline Serranidae & Serranus cabrilla & 0.015 & 0.119 \\
\hline Carangidae & Trachurus mediterraneus & 0.015 & 0.023 \\
\hline Sciaenidae & Umbrina cirrosa & 0.015 & 0.014 \\
\hline Myliobatidae & Myliobatis aquila & 0.013 & - \\
\hline Dasyatidae & Dasyatis pastinaca & 0.012 & 0.006 \\
\hline Mullidae & Mullus surmuletus & 0.012 & 0.087 \\
\hline Triglidae & Aspitrigla obscura & 0.007 & - \\
\hline Merlucciidae & Merluccius merluccius & 0.007 & 0.148 \\
\hline Carangidae & Trachurus trachurus & 0.007 & 0.006 \\
\hline Sparidae & Sarpa salpa & 0.006 & 0.000 \\
\hline Sparidae & Sparus aurata & 0.006 & 0.009 \\
\hline Trachinidae & Trachinus draco & 0.006 & - \\
\hline Sparidae & Diplodus vulgaris & - & 0.017 \\
\hline Triglidae & Lepidotrigla cavillone & - & 0.009 \\
\hline Sparidae & Pagellus bogaraveo & - & 0.042 \\
\hline Phycidae & Phycis blennoides & - & 0.010 \\
\hline Rajidae & Raja asterias & - & 0.045 \\
\hline Rajidae & Raja clavata & - & 0.003 \\
\hline Rajidae & Raja radula & - & 0.003 \\
\hline Scorpaenidae & Scorpaena notata & - & 0.006 \\
\hline Labridae & Symphodus tinca & - & 0.006 \\
\hline Triglidae & Trigla lucerna & - & 0.028 \\
\hline Triglidae & Trigla lyra & - & 0.003 \\
\hline Gadidae & Trisopterus luscus & - & 0.003 \\
\hline Gadidae & Trisopterus minutus & - & 0.026 \\
\hline Total & & 13.57 & 5.785 \\
\hline
\end{tabular}

CIMR boundary or 'adjacent grounds' (ADJ), and (4) fishing grounds located beyond $5 \mathrm{~km}$ from the CIMR boundary or 'far grounds' (FAR) (Fig. 1). For each spatial category we combined the samples from the whole study period. As we detected changes in abundance, biomass and diversity within the CIMR during the study period (see results on CIMR temporal change), one could object that combining data from the CIMR over the whole study period for comparisons with exploited zones may not be appropriate. However, we argue that by combining data the estimates of CIMR values will become more conservative and, thus, not hinder the interpretation of any community differences we have detected between the CIMR and fished zones.

Other obvious problems exist with a study of this kind. Firstly, only one marine protected area has been studied, so that the 'treatment' has not been replicated. Strictly speaking, samples taken within the CIMR for comparison with other locations are 'pseudoreplicates' (Hurlbert 1984). However, because the samples outside the CIMR are from similar nearby habitats (lobster fishing grounds) and they extend away from the CIMR in all directions (Fig. 1), at least partially mitigate this problem. Secondly, the sampling stations within the CIMR are, on average, closer to shallow water than those outside it, so that differences in species abundance, composition or diversity could result from habitat effects associated with shallow water environments. However, as described below, this was tested using 2-way significance tests (zone/distance from shallow water) and found not to be a problem. Prior to this, we did find that community composition at depths shallower than $50 \mathrm{~m}$ was different from that at greater depths, and therefore only CIMR samples from the deep stratum $(>50 \mathrm{~m}$ ) were used in the comparisons of the CIMR with fished zones.

Community development in exploited areas and spillover effects: To assess potential spillover effects of the CIMR on the adjoining fishery we examined the development of the fish community in each of the 3 exploited spatial categories described above using onboard fishery data.

Data analysis. Abundance and biomass: Abundance and biomass indices for the combined species were estimated by the catch per unit effort (CPUE) expressed in numbers (NCPUE) and weight (kg) (WCPUE) per $600 \mathrm{~m}$ of trammel net (standard length of experimental and commercial lobster trammel net fishing sets). The changes in abundance and biomass in the CIMR were tested using linear regression analyses of $\log _{10}(\mathrm{NCPUE}+1)$ and $\log _{10}(\mathrm{WCPUE}+1)$ as functions of time. One-way between-groups ANOVA was used to test for differences in $\log _{10}(\mathrm{NCPUE}+1)$ and squareroot transformed (WCPUE) in the CIMR and the fished 
zones. Homogeneity of variances was tested using Levene's test. Post-hoc comparisons were made using Tukey's honestly significant differences (HSD) test.

Diversity: To study the changes in species diversity, and to compare them between unfished and fished zones in each of the 9 yr studied, we used the following indices:

(1) Margalef's richness index (Margalef 1968):

$$
d=(S-1) /\left(\log _{\mathrm{e}} N\right),
$$

where $S$ is the total number of species and $N$ is the total number of individuals in the sample. As Margalef's index, $d$, is affected by the number of samples, for the spatial comparison we balanced sample size (number of fishing sets) between zones by removing randomly selected hauls as necessary.

(2) Simpson's evenness (dominance) index (Simpson 1949):

$$
1-\lambda=1-\left[\sum_{i} N_{i}\left(N_{i}-1\right)\right] /[N(N-1)],
$$

where $N_{i}$ is the number of individuals of the $i$ th species in the sample.

We also calculated the diversity indices $\Delta^{*}$ and $\Delta+$ based on taxonomic distinctness (Warwick \& Clarke 2001). We have focused on average taxonomic distinctness measures $\Delta^{*}$ and $\Delta+$, since average taxonomic diversity $(\Delta)$ has been shown in many studies (as it did in this one) to track species diversity measures such as Simpson's index quite closely. Thus, to remove the dominating effect of the species abundance distribution $\left(x_{i}\right)$, leaving a measure that is more nearly a pure reflection of the taxonomic hierarchy, $\Delta$ is divided by the Simpson's index, to give average taxonomic distinctness:

$$
\Delta^{*}=\left(\sum \sum_{i<j} \omega_{i j} x_{i} X_{j}\right) /\left(\Sigma \Sigma_{i<j} x_{i} X_{j}\right)
$$

Another form of the taxonomic distinctness index takes the special case where quantitative data are not available and the sample consists simply of a species list (presence/absence data). In this case, both $\Delta$ and $\Delta^{*}$ reduce to the same coefficient:

$$
\Delta+=\left(\sum \sum_{i<j} \omega_{i j}\right) /[S(S-1) / 2]
$$

where $S$ is the observed number of species in the sample and the double summation ranges over all pairs $i$ and $j$ of these species $(i<j)$. The average taxonomic distinctness, $\Delta+$, of a species list is the average taxonomic distance apart from all its pairs of species. Thus $\Delta+$ is an intuitive definition of biodiversity, as average taxonomic breadth of a sample. All the richness and diversity indices were calculated using only fishing sets in which the number of species present was in excess of 5, as plots of indices calculated using fewer species tend to give unreliable results (R. Warwick \& B. Stobart pers. obs.).
Size structure: To study the development of fish size in the CIMR and compare it across spatial categories we used a method based on the combined size structure of the 33 most abundant fishes, captured over time within the CIMR, and for all years combined across zones. This method has the advantage of allowing comparison of sizes of all species together, rather than individually, as is usually the case, and involves standardising the size of all individuals of each species with more than 2 individuals in the sample to a percentage of the maximum species-specific registered size (the maximum size of each species recorded, considering samples from all zones). For convenience, we refer to the percentage output as 'relative body size.' While this does not relate the sizes to the maximum attainable size for each species, e.g. those given in FishBase (available at www.fishbase.org), it removes the need to use size data that may have origins in other areas where fish maximum sizes can be very different from those attainable locally. The development of the size structure within the CIMR was explored using linear regression of the annual mean relative body size. The significance of the inter-annual slope was tested by ANOVA of the arcsine transformed percentages.

The size structure of the community in the CIMR (deep stratum only) was then compared with that of the fished zones by constructing size frequency distributions for each zone with all years combined and with each data set standardised to the zone total to eliminate differences in sample size. Resulting frequency distributions for zones were compared using nonparametric Kolmogorov-Smirnov tests. For species with sufficient number of individuals, change in body size over time was studied by linear regression analysis.

Trophic level: Mean community trophic level was calculated using data of the 51 fish species based on trophic categories obtained from Fishbase and Konstantinos \& Vasiliki (2002). Changes in mean trophic level over time in the CIMR and the fished zones were explored using linear regression analysis while interzone differences were assessed using the nonparametric Kruskal-Wallis test.

Species composition: To examine differences in community species composition over time within the CIMR and between spatial categories, we used nonmetric multidimensional scaling ordination (MDS) with square-root transformed species abundance or biomass and the Bray-Curtis measure of similarity between samples. Temporal change of the communities in the different zones was tested by comparing yearly average points on an MDS to a linear sequence or seriation (e.g. see Clarke et al. 1993 for full explanation of the test). We used SIMPER analysis in PRIMER v. 6 to identify those species contribut- 

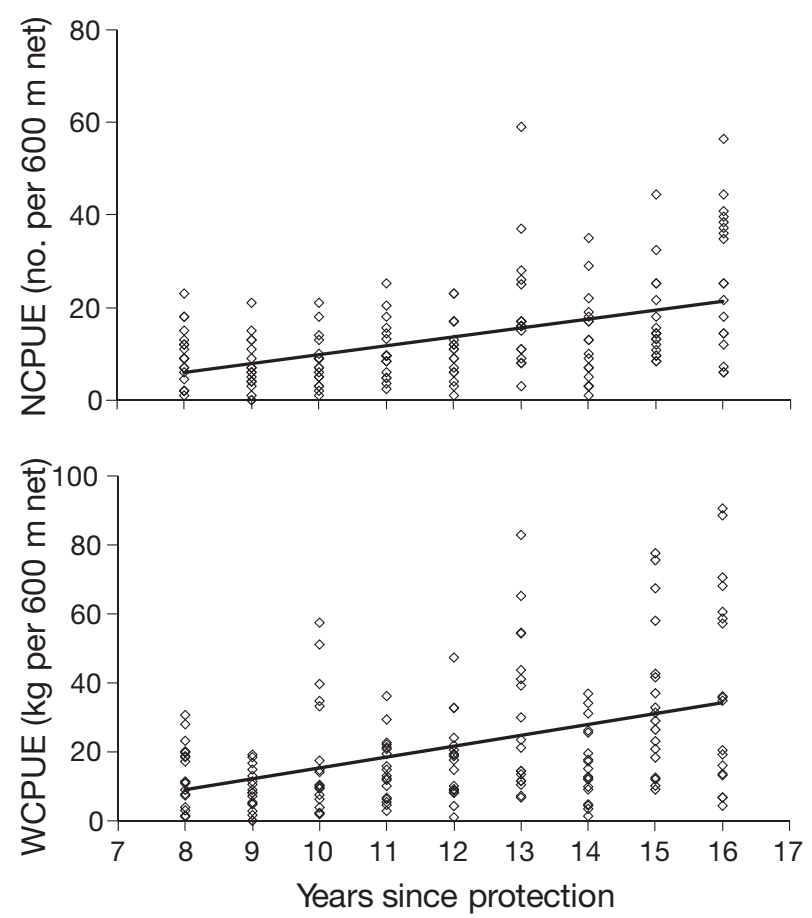

Fig. 2. Abundance (catch per unit effort in numbers, NCPUE) and biomass (catch per unit effort in weight, WCPUE) of the fish community within the CIMR as function of time (years)

ing to the dissimilarity between years within the CIMR, and the BVSTEP routine to determine which were the main species driving the temporal change. Two-way analysis of similarities (ANOSIM) was used to test for the degree of dissimilarity between zones across the different years, across sampling months (since the time of fishing varied from year to year among zones) and in relation to distance from shallow water. For the latter, distance to the nearest $40 \mathrm{~m}$ depth contour was divided into 4 categories: $<1 \mathrm{~km}$, 1-5 km, 5-15 km and 15-30 km. Two-way SIMPER was used to identify those species responsible for characterising each zone, and contributing to the dissimilarity between zones, across the 9 yr. Variability among samples within each zone was compared using the PRIMER routine MVDISP, which gives a value for relative multivariate variability within each group, as increased variability among samples has been regarded as a multivariate symptom of stress in marine communities (Warwick \& Clarke 1993). The degree to which community development within the CIMR corresponds with a linear sequence was tested using the PRIMER routine RELATE. The multivariate techniques used are described fully by Clarke \& Warwick (2001) and have been implemented using PRIMER v. 6 (Clarke \& Gorley 2006).

\section{RESULTS}

\section{Community change within the CIMR}

Linear trends in univariate measures of the exploited fish community within the CIMR (Fig. 2, Table 2) indicated significant increases over time in both abundance and biomass. Slopes of regression analysis of species diversity in terms of richness (Margalef's $d$ ) and evenness (Simpson's $1-\lambda$ ) as a function of time were positive though not significant. In contrast, both taxonomic distinctness indices, $\Delta^{*}$ and $\Delta+$, showed significant decreases during the study period (Table 2), though the decrease was driven by Mullus surmuletus, a single representative of the family Mullidae, present only in the early years. Removal of this species from the analyses led to a non-significant decreasing trend.

Fish relative body size in the CIMR (mean of 33 fish species selected) increased significantly with time $\left(\mathrm{R}^{2}=0.009, F_{1,2504}=22.9, \mathrm{p}<0.001\right.$ ) (Fig. 3). Relative mean fish sizes in the years 2004 and 2005 were particularly large, while in 2006 mean size was low. For 2004 this anomaly was caused by catches of unusually large individuals of Raja brachyura, while variation in 2005

Table 2. Results of linear regression analyses of log abundance $(\mathrm{NCPUE}+1)(\log N), \log$ biomass $(\mathrm{WCPUE}+1)(\log$ Biom) and richness and diversity indices as a function of years of protection of the exploited fish community in the CIMR (20 to $100 \mathrm{~m}$ depth). Significant $\mathrm{p}$-values are in bold

\begin{tabular}{|lrcrrr|}
\hline Factor & $\mathrm{n}$ & $\mathrm{R}^{2}$ & Slope $b$ & $t$-statistic & $\mathrm{p}$-value \\
\hline LogN & 163 & 0.218 & 0.057 & 6.423 & $<\mathbf{0 . 0 0 1}$ \\
LogBiom & 163 & 0.183 & 0.062 & 5.752 & $<\mathbf{0 . 0 0 1}$ \\
Margalef's d & 71 & 0.031 & 0.037 & 1.505 & 0.137 \\
Simpson's 1- $\lambda^{\prime}$ & 71 & 0.009 & 0.004 & 0.798 & 0.428 \\
$\Delta^{*}$ & 71 & 0.065 & -0.729 & -2.197 & $\mathbf{0 . 0 3 1}$ \\
$\Delta+$ & 71 & 0.064 & -0.471 & -2.175 & $\mathbf{0 . 0 3 3}$ \\
\hline
\end{tabular}

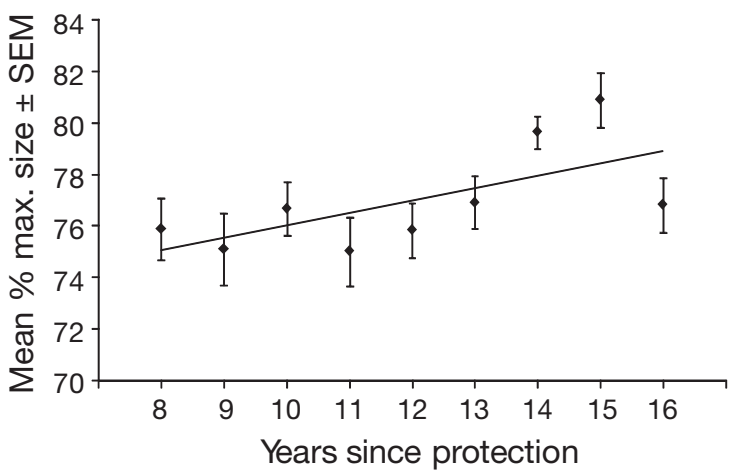

Fig. 3. Mean percentage of maximum size \pm SE of the mean (SEM) as a function of time (years) since protection for the 33 most abundant fish species sampled inside the CIMR 
and 2006 was general and not attributable to a single species. Only 8 fish species were caught in sufficient numbers to analyse change in body size over time on an individual basis. Of these, Scorpaena scrofa $\left(\mathrm{R}^{2}=\right.$ 0.028, $\left.F_{1,610}=17.95, \mathrm{p}<0.001\right)$, Pagellus erythrinus $\left(\mathrm{R}^{2}=0.138, F_{1,34}=6.48, \mathrm{p}=0.02\right)$, Phycis phycis $\left(\mathrm{R}^{2}=\right.$ $\left.0.061, F_{1,178}=11.7, \mathrm{p}<0.001\right)$ and Sciaena umbra $\left(\mathrm{R}^{2}=\right.$ 0.037, $F_{1,110}=4.24, \mathrm{p}=0.04$ ) significantly increased in size over time, while Scyliorhinus stellaris $\left(\mathrm{R}^{2}=0.071\right.$, $F_{1,68}=5.20, \mathrm{p}=0.03$ ) decreased. Trends for the remaining 3 species, while not significant, suggested that Dentex dentex may be increasing in size $\left(\mathrm{R}^{2}=0.013\right.$, $F_{1,69}=0.95, \mathrm{p}=0.33$ ) while sizes of Lophius piscatorious $\left(\mathrm{R}^{2}=0.022, F_{1,59}=1.35, \mathrm{p}=0.25\right)$ and Zeus faber $\left(\mathrm{R}^{2}=0.008, F_{1,173}=1.49, \mathrm{p}=0.22\right)$ may be decreasing.

Mean trophic level of the community within the CIMR increased over time, though the trend was slightly below the significant threshold $\left(\mathrm{R}^{2}=0.02\right.$, $F_{1,105}=3.57, \mathrm{p}=0.062$ ). MDS plots for all samples averaged in each year (not shown) indicated significant linear trends (seriation) over time in fish species composition, both in terms of abundance and biomass ( $p<0.02$ in all cases). BVSTEP analysis revealed that Lophius budegassa, L. piscatorius, Phycis phycis, Raja montagui, R. polystigma, Scorpaena scrofa, Scyliorhinus stellaris and Zeus faber correlated at the $95 \%$ level with the pattern produced, and are therefore the species driving the change. There were no significant results for seriation outside the CIMR (not shown), although the BOR area was almost significant ( $\rho=$ $0.272, \mathrm{p}=0.086)$, while the ADJ and FAR areas were not $(\rho=0.005, p=0.46$ and $\rho=0.048, p=0.41$ respectively).

\section{Comparison between the CIMR and fished areas and spillover effects}

Mean abundance and biomass of the fish community pooled for the entire study period differed significantly between zones (abundance $F_{3,433}=14.35$, p $<0.001$, biomass $F_{3,433}=20.79$, p < 0.001) (Fig. 4). Post-hoc comparisons indicated that abundance was significantly higher inside the CIMR (mean \pm SD NCPUE $=10.4 \pm$
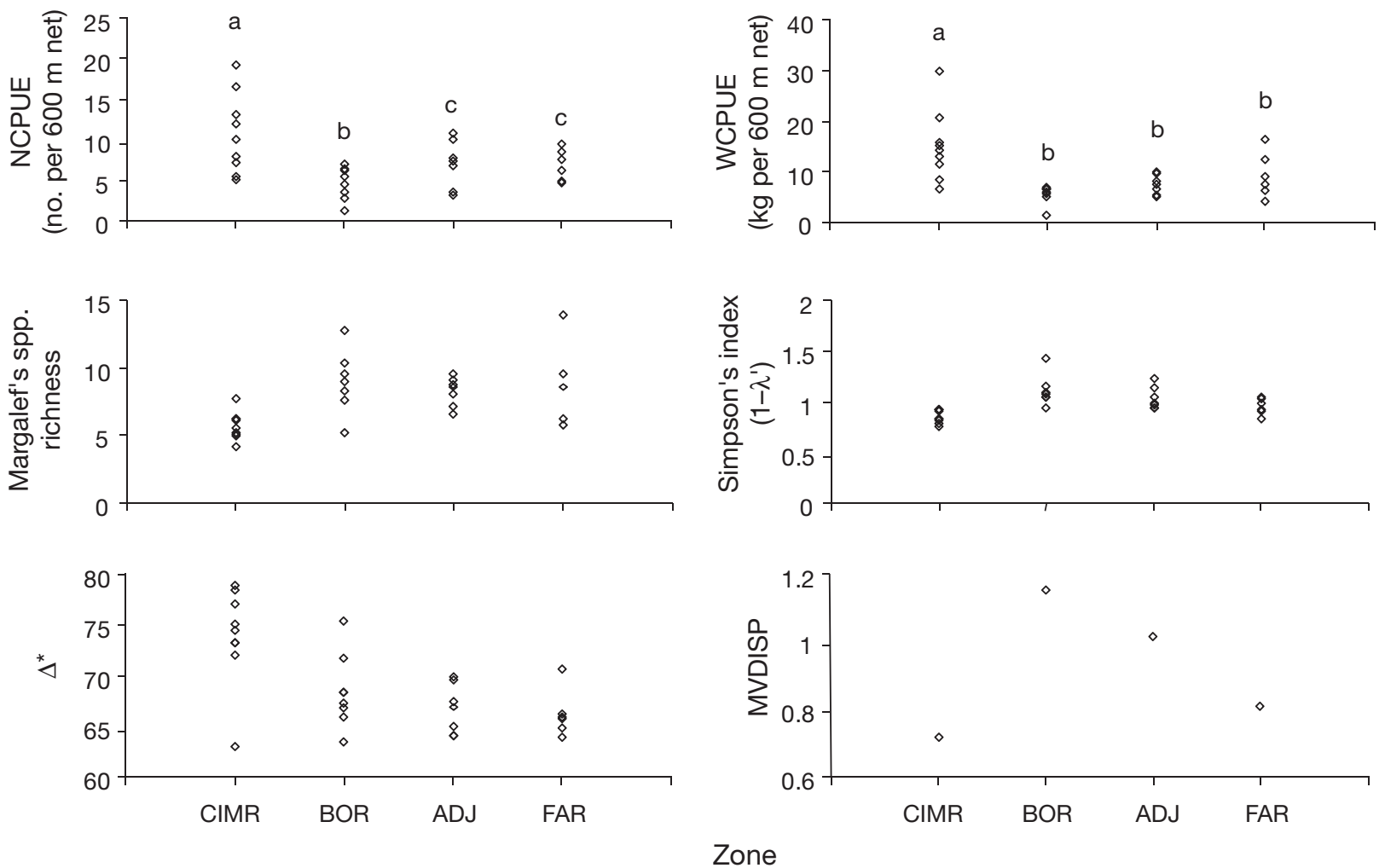

Fig. 4. Annual univariate means of catch per unit effort in numbers (NCPUE) or weight (WCPUE) per 600 m net, Margalef's species richness, Simpson's diversity index, and delta taxonomic distinctness and multivariate dispersal (MVDISP) of the fish community by zone: BOR (border grounds, $<0.5 \mathrm{~km}$ from CIMR boundary), ADJ (adjacent grounds, 0.5 to $5 \mathrm{~km}$ from boundary) and FAR (far grounds, 5 to $30 \mathrm{~km}$ from boundary). Letters indicate significant ( $\mathrm{p}=0.05$ level) difference among sites for NCPUE and WCPUE, according to pairwise comparisons (Tukey's HSD test) 
8.7) than in the fished zones (BOR mean $=4.8 \pm 4.4$, $\mathrm{ADJ}$ mean $=7.4 \pm 8.5$, FAR mean $=6.3 \pm 4.7$ ) and also that fish abundance in the BOR was significantly lower than in the ADJ and FAR zones, while the latter 2 zones were not significantly different from each other. Fish biomass was also higher in the CIMR (mean \pm SD WCPUE $=14.4 \pm 13.7)$ than in the fished zones (BOR mean $=5.7 \pm 6.5$, ADJ mean $=7.3 \pm 7.9$, FAR mean $=$ $7.5 \pm 7.2$ ), and was lower in the BOR than in the farther
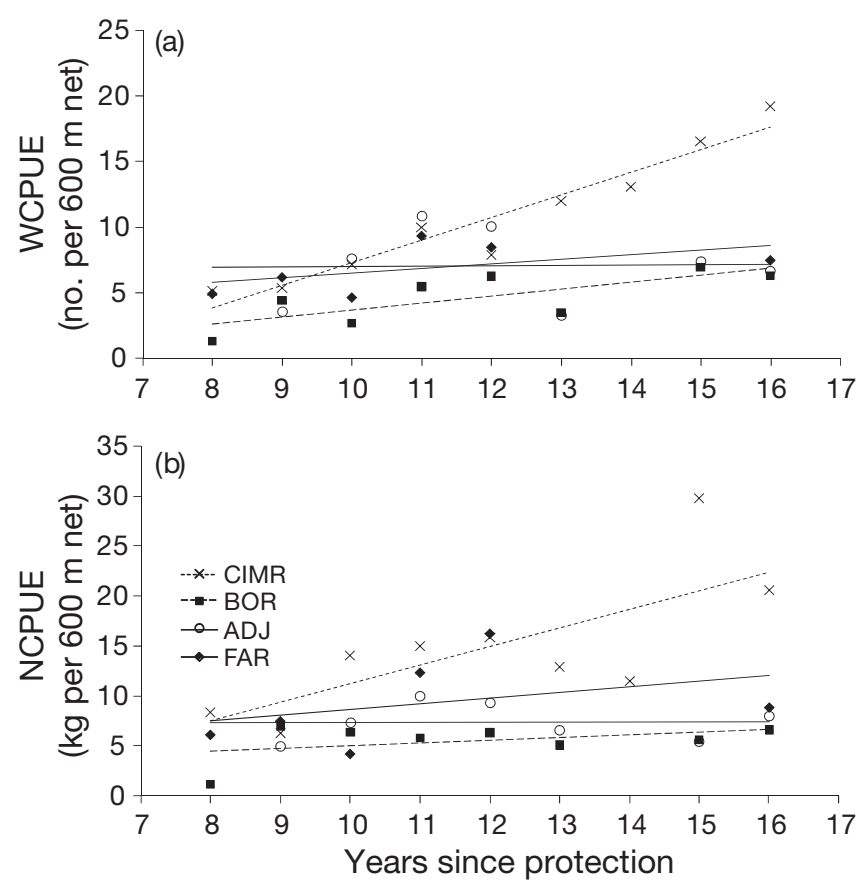

Fig. 5. (a) NCPUE and (b) WCPUE of the fish community as a function of time (years) in the CIMR and nearby fished zones (BOR, ADJ and FAR). Zone definitions and other information as in Fig. 4

Table 3. Results of linear regression analyses of log abundance (NCPUE +1 ) and log biomass (WCPUE + 1) as a function of years of protection of the exploited fish community in the CIMR and fished zones (50 to $100 \mathrm{~m}$ depth range). BOR: border grounds, ADJ: adjacent grounds, FAR: far grounds (see text for details). Significant p-values are in bold

\begin{tabular}{|lrcccr|}
\hline Factor & $\mathrm{n}$ & $\mathrm{R}^{2}$ & Slope $b$ & $t$-statistic & $\mathrm{p}$-value \\
\hline Abundance & & & & & \\
CIMR & 88 & 0.268 & 0.068 & 5.621 & $\mathbf{< 0 . 0 0 1}$ \\
BOR & 157 & 0.085 & 0.052 & 3.810 & $\mathbf{< 0 . 0 0 1}$ \\
ADJ & 95 & 0.008 & 0.013 & 0.875 & 0.383 \\
FAR & 97 & 0.033 & 0.023 & 1.827 & 0.071 \\
Biomass & & & & & \\
CIMR & 88 & 0.181 & 0.061 & 4.367 & $<\mathbf{0 . 0 0 1}$ \\
BOR & 157 & 0.037 & 0.040 & 2.454 & $\mathbf{0 . 0 1 5}$ \\
ADJ & 95 & 0.003 & 0.009 & 0.584 & 0.560 \\
FAR & 97 & 0.015 & 0.020 & 1.224 & 0.224 \\
& & & & & \\
\hline
\end{tabular}

fished zones, although not significantly (Fig. 4). Examined over time, abundance and biomass indices of the fish community in the CIMR increased continuously during the study period and to a lesser extent in the BOR and FAR zones, while there was no change in the ADJ zone (Fig. 5, Table 3). The trend was only significant in the CIMR and BOR zones.

Fish species diversity indices also differed between the CIMR and fished zones. Species richness (Margalef's $d$ ) and evenness (Simpson's $1-\lambda$ ) had lowest values inside the CIMR and highest at the border zone, with a subsequent weak decline with increasing distance from the CIMR (Fig. 4). In contrast, average taxonomic distinctness measures $\Delta^{*}$ and $\Delta+$ were highest in the CIMR and declined progressively from the BOR, to both the ADJ and FAR zones (Fig. 4).

Frequency distributions of fish relative body size showed that fish were significantly larger inside the CIMR than in the fished zones, while distributions

Table 4. Results of Kolmogorov-Smirnov 2-sample tests of frequency distributions of relative fish body size between zones. Zone abbreviations are defined in Table 3. Significant $\mathrm{p}$-values are in bold

\begin{tabular}{|lrr|}
\hline Zone comparison & Z-statistic & p-value \\
\hline CIMR/BOR & 8.567 & $\mathbf{< 0 . 0 0 1}$ \\
CIMR/ADJ & 10.745 & $<\mathbf{0 . 0 0 1}$ \\
CIMR/FAR & 12.688 & $<\mathbf{0 . 0 0 1}$ \\
BOR/ADJ & 1.177 & 0.125 \\
BOR/FAR & 1.034 & 0.236 \\
ADJ/FAR & 0.713 & 0.690 \\
\hline
\end{tabular}

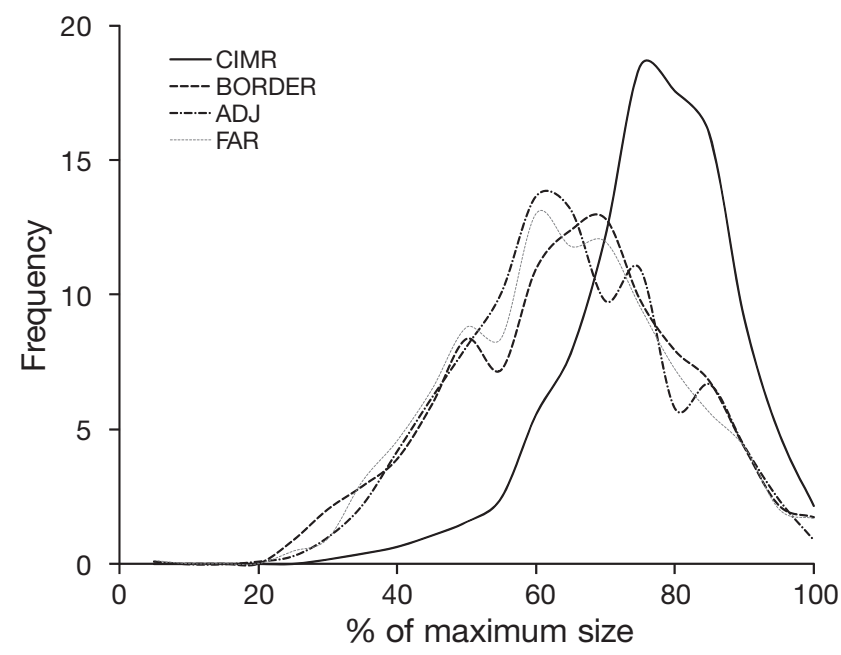

Fig. 6. Percent frequency distributions of relative fish size (expressed as a percentage of the maximum size observed) in the CIMR and nearby fished zones (BOR, ADJ and FAR) (all years combined). Zone definitions and other information as in Fig. 4 
were not significantly different among the fished zones (Fig. 6, Table 4). Though fish size distribution at the border did not differ significantly from the other fished zones (Table 4), the distribution did lie between these zones and the CIMR, indicating that the community at the border contained a greater proportion of larger fish than those in the adjacent and far zones (Fig 6).

Initial Kruskal-Wallis analysis revealed that the community in the CIMR had a significantly lower mean trophic level than in the fished zones $\left(\chi^{2}=28.34, \mathrm{df}=3\right.$, $\mathrm{p}<0.001$ ). However, the difference was driven by the presence of large catches of the ray Raja montagui within the CIMR, as this species has a relatively low trophic level. When this species was removed from the analyses, there was no difference in mean trophic level between the CIMR and the exploited areas.

Further evidence of differences between the fish communities in the CIMR and fished zones was apparent in the measure of multivariate dispersion (MVDISP), which was lowest inside the CIMR and highest at the border (Fig. 4). MDS plots of yearly averages per zone also showed clear separation of species composition between the CIMR and nearby fished zones (Fig. 7). Two-way ANOSIM tests using zone as one factor and either year, sampling month or distance to the $40 \mathrm{~m}$ depth contour as the other, all showed much larger ANOSIM R statistic values for zones than for the other factors (Table 5). Indeed, there was no significant effect of distance from shallow water, with values of the R statistic close to zero. In pairwise zone tests the $\mathrm{R}$ statistic was greatest between the CIMR and other zones, and tended to decline in value with increasing distance from the CIMR. Two-way SIMPER analysis with zone and year as factors indicated that the main species accounting for the difference between the CIMR and the BOR, ADJ and FAR zones were Scorpaena scrofa, Raja montagui, Zeus faber and Lophius piscatorius.

\section{DISCUSSION}

\section{Community change within the CIMR}

The recovery time for exploited species in MPAs has important implications for the design of such areas and the management of fisheries (McClanahan et al. 2007). Our results clearly indicate that the exploited fish community in the CIMR changed continuously during the period of 8 to $16 \mathrm{yr}$ after fishing ceased. This temporal change was patent in most community variables studied, with increasing trends of fish abundance and biomass, average body size and, to a lesser extent, changes in species composition. The changes in abundance and species composi-
Table 5. Results of 2-way ANOSIM for fish community differences between year and month groups and distance to $40 \mathrm{~m}$ isobath across all zones, and for zone groups across all years, months and distance to $40 \mathrm{~m}$ isobath. Zone abbreviations are defined in Table 3

\begin{tabular}{|c|c|c|c|}
\hline Comparison & Groups & Sample statistic & $\mathrm{p}$-value \\
\hline \multirow[t]{8}{*}{ Years } & Global year & 0.084 & $<0.001$ \\
\hline & Global zone & 0.079 & $<0.001$ \\
\hline & CIMR/BOR & 0.055 & 0.132 \\
\hline & CIMR/ADJ & 0.167 & $<0.001$ \\
\hline & CIMR/FAR & 0.228 & $<0.001$ \\
\hline & $\mathrm{BOR} / \mathrm{ADJ}$ & 0.01 & 0.349 \\
\hline & BOR/FAR & 0.085 & 0.015 \\
\hline & ADJ/FAR & 0.066 & 0.033 \\
\hline \multirow[t]{8}{*}{ Months } & Global month & 0.048 & 0.038 \\
\hline & Global zone & 0.148 & $<0.001$ \\
\hline & CIMR/BOR & 0.27 & $<0.001$ \\
\hline & CIMR/ADJ & 0.368 & $<0.001$ \\
\hline & CIMR/FAR & 0.264 & $<0.001$ \\
\hline & $\mathrm{BOR} / \mathrm{ADJ}$ & -0.009 & 0.606 \\
\hline & BOR/FAR & 0.067 & $<0.001$ \\
\hline & ADJ/FAR & 0.0 & 0.471 \\
\hline \multirow[t]{8}{*}{ Distance } & Global distance & 0.003 & 0.435 \\
\hline & Global zone & 0.085 & $<0.001$ \\
\hline & CIMR/BOR & 0.141 & $<0.001$ \\
\hline & CIMR/ADJ & 0.155 & 0.036 \\
\hline & CIMR/FAR & 0.321 & $<0.001$ \\
\hline & $\mathrm{BOR} / \mathrm{ADJ}$ & 0.015 & 0.232 \\
\hline & BOR/FAR & -0.105 & 0.983 \\
\hline & ADJ/FAR & -0.155 & 0.998 \\
\hline
\end{tabular}

tion within the CIMR were also evident in the MDS plots, which showed directional change over time and were in stark contrast to our findings outside the CIMR, where there was no evidence of directional change (but see comments on BOR below). Our results are consistent with previous studies of longterm monitoring of MPA fish populations (Russ et al. 2004), space-for-time substitution (Russ et al. 2005, McClanahan et al. 2007) and some meta-analytical work (e.g. Claudet et al. 2008), which indicate that fish density increases with length of time of protection. However, our studies contradict those that show mean responses to protection in MPAs in terms of biomass, mean size or diversity are reached within a few years (Roberts et al. 2001, Halpern \& Warner 2002). Our results also show that a stable state had not yet been reached within the CIMR after $16 \mathrm{yr}$ of protection, and that the community properties will most probably continue to change, which again supports studies that suggest recovery can take decades (e.g. Russ et al. 2005, McClanahan et al. 2007).

Abundance and biomass of the exploited fish community grew at an average rate of 14 and $16 \%$ per year, respectively, during the study period, without indication of an asymptote. This response has been 


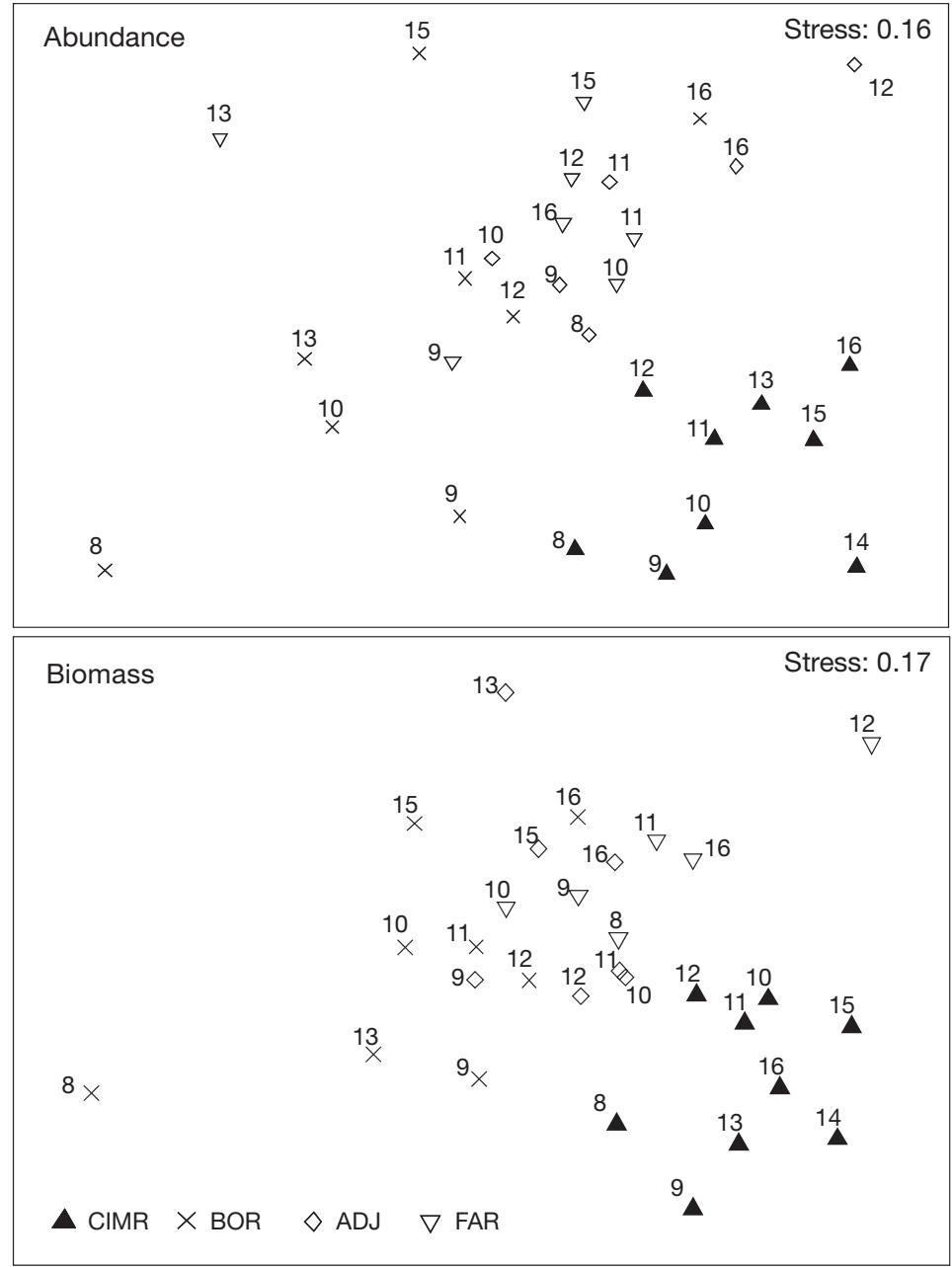

Fig. 7. Multidimensional scaling (MDS) plots of annual average abundance (NCPUE, no. fish per $600 \mathrm{~m}$ net) and biomass (WCPUE, kg per $600 \mathrm{~m}$ net) of the fish community, with samples represented by zone symbols (CIMR, BOR, ADJ, FAR) and labelled by years since protection.

Zone definitions and other information as in Fig. 4

documented in numerous studies in temperate and tropical MPAs (e.g. Sánchez-Lizaso et al. 2000, Russ 2002). Also, as seen in previous studies and model predictions (e.g. Rakitin \& Kramer 1996), fish species contributing most to the biomass build up in the CIMR were highly catchable species of restricted to moderate mobility and low resilience, such as the largescale scorpionfish Scorpaena scrofa, rays Raja montagui and R. polystigma, and the great forkbeard Phycis phycis (see FishBase). Abundance and biomass in the CIMR increased faster in the latter half of the study period than they did in the earlier half. This may be evidence that recreational fishing, allowed in the CIMR until 2004 (but effectively ceased in 2002 when anchoring was prohibited), had a measurable effect on fish popu- lations. In the CIMR, recreational fishing targets predatory fish (S. scrofa, Dentex dentex, and $P$. phycis amongst others), which constitute the most valuable bycatch of the spiny lobster trammel net fishery. Recreational fishing, even at relatively low levels, such as allowed in the Columbretes Island Marine Reserve, is known to have a measurable effect on fish populations (e.g. Coleman et al. 2004, Kleczkowski et al. 2008); which strongly supports the need for full fishing closures and good enforcement of MPAs (Guidetti et al. 2008).

Average body size and trophic level of the community also increased during the study period. The progressive growth in the proportion of large fishes in protected populations has been documented in many studies of MPAs in tropical (e.g. Galal et al. 2002, Kaunda-Arara \& Rose 2004) and temperate reefs (Harmelin et al. 1995, Tetreault \& Ambrose 2007), and is a direct consequence of the reduction of fishing mortality and size-selective fishing (Jennings \& Kaiser 1998). Predator removal is one of the most widespread and well-documented direct effects of fishing (Jennings \& Kaiser 1998). Thus, in relatively large and well-protected MPAs, such as the CIMR, the observed positive relationship of fish mean trophic level (TL) and time of protection was expected. Most fish species consistently appearing in the CIMR catches are macrocarnivores with trophic levels ranging from 3.30 to 4.55 , according to available information (FishBase). The majority of these fishes have gradually increased in abundance over the study period, some remaining low at the beginning and increasing markedly in the later years of the study, among them two with a relatively high $\mathrm{TL}$, Zeus faber $(\mathrm{TL}=4.40)$ and Raja polystigna (TL $=3.97)$.

\section{Comparison between the CIMR and fished areas}

The comparison of the exploited fish communities in the CIMR with those in fished zones at increasing distances from the CIMR revealed remarkable differences in the patterns of the community variables studied. Firstly, abundance and biomass were highest inside the CIMR and lowest in the border zone, confirming both the predicted recovery of exploited populations inside the CIMR and the local depletion caused 
by commercial effort concentration along the CIMR boundaries. The higher abundance and biomass inside the CIMR in this study was to be expected, as recovery of abundance and biomass of exploited species inside MPAs is an established and widespread phenomenon (Russ 2002, Tetreault \& Ambrose 2007) and well studied in Mediterranean MPAs (e.g. García-Charton et al. 2004, Ojeda-Martinez et al. 2007, Harmelin-Vivien et al. 2008). However, although predicted by theory (Walters et al. 2002, Kellner et al. 2007), only a handful of studies have so far documented local depletion of catch rates as a result of effort concentration along MPA boundaries (e.g. MacClanahan \& Mangi 2000, Kaunda-Arara \& Rose 2004), as observed in this study and the previous study of the lobster fishery around the CIMR (Goñi et al. 2006).

Secondly, the opposite pattern was observed in species richness and diversity and multivariate dispersion (MVDISP), with highest values at the border and lowest inside the CIMR. In the present study lower species richness and evenness were evident inside the CIMR and both were highest in the most heavily fished zone (border), which seems counter intuitive. There is good evidence that fishing leads to depletion of species richness (e.g. Jennings \& Kaiser 1998, Hall 1999) and several studies report greater species richness inside MPAs (e.g. Cote et al. 2001, Kaunda-Arara \& Rose 2004) or adjacent to MPAs (e.g. Russ \& Alcala 1996, McClanahan \& Mangi 2000) relative to those in control fished areas. However, there is also evidence to indicate that in some cases fishing may also increase diversity (Bianchi et al. 2000). In our study the lower richness and diversity in the CIMR could be explained by the fact that common bycatch fish species have increased dramatically inside the CIMR, while other species that are occasionally caught in lobster trammel nets have not increased (e.g. Serranus cabrilla, Sparus aurata), which could lower the value of these indices. In the fished zones, target and main bycatch species have been reduced comparatively more than have species that are occasionally caught, which has the effect of increasing Margalef's richness index (due to lower abundance of fish) and Simpson's evenness index (due to less difference in abundance between species). Nevertheless, recent studies of temperate exploited communities warn that the response of diversity indices to fishing is not straightforward (Rochet \& Trenkel 2003, Piet \& Jennings 2005). Finally, the pattern of multivariate dispersion (MVDISP) we have observed coincides with studies that report high variability in catches near MPAs (e.g. Abesamis \& Russ 2005, Goñi et al. 2006), while greater stability within the CIMR as suggested by MVDISP seems logical as greater year-to-year variation in yields is expected in perturbed systems (Murawski 2000).
A third pattern was observed in taxonomic distinctness $\left(\Delta^{*}\right.$ and $\left.\Delta+\right)$, which, in contrast to fish species diversity measures, responded positively to protection afforded by the CIMR, with intermediate values at the border and lowest in the adjacent and far zones. We considered that the presence of the ray Raja montagui in large numbers inside the CIMR, but rarely outside, could have been the origin of this difference. However, removal of $R$. montagui and subsequently all other rays from the calculation of these indices did not change the trend. Within the Mediterranean Sea Gristina et al. (2006) also found that heavily fished areas showed significantly lower $\Delta^{*}$ and $\Delta+$ values than areas of no or low fishing pressure. On the other hand, Blanchard et al. (2004) found no difference between these indices in strongly versus moderately exploited areas of the Bay of Biscay. Again, conflicting results suggest that further research is needed on the responses of these indices to fishing.

\section{Spillover}

The increasing trends in abundance and mean fish size within the CIMR translated into similar upward trends in the yields of the fishery immediately adjacent to the CIMR, providing evidence of the build-up of spillover over time. Among studies that have documented the building up of a spillover effect adjacent to an MPA (e.g. Russ \& Alcala 2004, Barrett et al. 2007), ours is the only one that shows this development in conjunction with concentration of fishing effort near an MPA boundary (fishing the line) as documented by Goñi et al. (2006). The combined effect of the 2 processes was local overfishing, with locally depleted, but continuously increasing CPUE at the border $(<0.5 \mathrm{~km}) 8$ to 16 yr after CIMR creation without a sign of reaching an asymptote. The upward trend in the border fishery yields was more marked in abundance than biomass and was not apparent in the adjacent $(0.5$ to $5 \mathrm{~km})$ and far $(>5 \mathrm{~km})$ fished zones. While one could argue that CPUE may have increased over time at the border if overall fishing effort was decreasing, we believe that overall fishing effort has remained stable over the study period. This view is supported by the lack of significant temporal trends in abundance and biomass in the adjacent and far fished zones, suggesting that fishing effort in the area has remained stable over the study period. The previous study on lobster spillover from the CIMR showed that about $75 \%$ of the commercial fishing effort in the area was deployed within $1 \mathrm{~km}$ from the CIMR and also demonstrated local depletion of lobster yields near the boundary relative to farther away $(1.5 \mathrm{~km}$ ) (Goñi et al. 2006). 
The fact that the distribution of fish relative body size in the border area lies between that of the CIMR, with the greatest proportion of large individuals, and those of the adjacent and far areas also suggests spillover effects robust to local overfishing. Spillover is also indicated by the 2 measures of taxonomic distinctness that were intermediate between the CIMR and other fished areas, and the fact that the border community followed a nearly significant pattern of seriation, while there was no pattern evident in the adjacent and far zones. Most of the available evidence of spillover comes from spatial comparisons or gradients away from MPAs, with higher catch rates (e.g. Rakitin \& Kramer 1996, Russ \& Alcala 1996) or catch per unit area (McClanahan \& Mangi 2000, Goñi et al. 2006, 2008) of exploited species immediately adjacent to MPA boundaries. In recent years results of studies that examined the development of fish yields or biomass adjacent to MPAs have become available. In an 18 yr study, Russ et al. (2004) found that evidence of spillover close to the Apo reserve was only detectable $8 \mathrm{yr}$ after its establishment. Galal et al. (2002) also reported significant increases in abundance and average size of many targeted reef fishes in 2 of 5 no-take reserves in the Red Sea, with CPUE in the adjacent fished areas increasing by two-thirds over a 5 yr period.

In conclusion, $16 \mathrm{yr}$ after fishing ceased in the Columbretes Islands Marine Reserve, the effects of protection on the exploited fish community were patent and continued to evolve without signs of reaching equilibrium. Fish community trends in abundance, biomass, size structure and species composition were clear, while causes of observed patterns of diversity were more uncertain. The exploited fish community in this MPA and nearby fished zones showed clear differences for most community indicators used. Several indicators show that the fished zone bordering the CIMR is a transitional zone between the CIMR and the fished zones farther away, and that spillover continues to increase in unison with biomass inside the CIMR. In terms of effects of protection on biodiversity, the observed patterns of diversity indices within the CIMR and between zones highlight the need for cautious interpretation. Lower values of traditional species richness (Margalef) and evenness (Simpson) indices within the CIMR would suggest a deleterious effect of protection, while higher taxonomic distinctness measures in the CIMR suggest the opposite. It is becoming clear that species richness and evenness measures alone can be misleading when assessing and evaluating biodiversity change, since, among other limitations, they are heavily dependent on the relative abundances of one or a few dominant species (e.g. Warwick et al. 2002). In making such assessments it is, therefore, helpful to examine as many aspects of biodiversity as possible to reduce the chance of misinterpretation. The use of population recovery data in MPAs has been hindered by the inability to study well-enforced closed areas over sufficiently long periods in conjunction with suitable control sites (McClanahan et al. 2007). Our study provides a unique case of long-term development in an MPA and comparable fished areas and lends support for the contention that recovery rates are slower and responses stronger than suggested by many short-term studies.

Acknowledgements. We thank the skippers and crews of the 'Calypso', 'Nou Calypso' and 'Catala' for their invaluable collaboration. We also thank Toni Quetglas for his role in field data collection. This work was funded by the Spanish Secretaria General del Mar by means of a grant for the LANGOSTA project (1997-2008). B.S. was supported by the European EMPAFISH project (2006-2008).

\section{LITERATURE CITED}

Abesamis RA, Russ GR (2005) Density-dependent spillover from a marine reserve: long-term evidence. Ecol Appl 15: 1798-1812

Barrett NS, Edgar GJ, Buxton CB, Haddon M (2007) Changes in fish assemblages following 10 years of protection in Tasmanian marine protected areas. J Exp Mar Biol Ecol 345:141-157

Bianchi G, Gislason H, Graham K, Hill L and others (2000) Impact of fishing on size composition and diversity of demersal fish communities. ICES J Mar Sci 57:558-571

Blanchard F, LeLoc'h F, Hily C, Boucher J (2004) Fishing effects on diversity, size and community structure of the benthic invertebrate and fish megafauna on the Bay of Biscay coast of France. Mar Ecol Prog Ser 280:249-260

> Borges TC, Erzini K, Bentes L, Costa ME and others (2001) By-catch and discarding practices in five Algarve (southern Portugal) métiers. J Appl Ichthyol 17:104-114

Clarke KR, Gorley RN (2006) PRIMER v6: User Manual/Tutorial. PRIMER-E, Plymouth

Clarke KR, Warwick RM (2001) Change in marine communities: an approach to statistical analysis and interpretation, 2nd edition. PRIMER-E, Plymouth

Clarke KR, Warwick RM, Brown BE (1993) An index showing breakdown of seriation, related to disturbance, in coralreef assemblages. Mar Ecol Prog Ser 102:153-160

Claudet J, Osenberg CW, Benedetti-Cecchi L, Domenici P and others (2008) Marine reserves: size and age do matter. Ecol Lett 11:481-489

Coleman FC, Figueira WF, Ueland JS, Crowder LB (2004) the impact of United States recreational fisheries on marine fish populations. Science 305:1958-1960

Colloca F, Crespi V, Cesari S, Coppola SR (2004) Structure and evolution of the artisanal fishery in a southern Italian coastal area. Fish Res 69:359-369

Cote IM, Mosqueira IE, Reynolds JD (2001) Effects of marine reserve characteristics on the prediction of fish populations: a meta-analysis. J Fish Biol 59:178-189

FAO (Fisheries and Agriculture Organization of the United Nations) (2007) The state of the world fisheries. FAO, Rome (ftp://ftp.fao.org/docrep/fao/009/a0699e)

Galal N, Ormond RFG, Hassan O (2002) Effect of a network of 
no-take reserves in increasing catch per unit effort and stocks of exploited reef fish at Nabq, South Sinai, Egypt. Mar Freshw Res 53:199-205

García-Charton JA, Pérez-Ruzafa A, Sánchez-Jerez P, BayleSempere JT, Reñones O, Moreno D (2004) Multi-scale heterogeneity, habitat structure, and effect of marine reserves on Western Mediterranean rocky reef fish assemblages. Mar Biol 144:161-182

García-Charton JA, Pérez-Ruzafa A, Marcos C, Claudet J and others (2008) Effectiveness of European Atlanto-Mediterranean MPAs: Do they accomplish the expected effects on populations, communities and ecosystems? J Nat Conserv 16:193-221

Goñi R, Latrouite D (2005) review of the biology, ecology and fisheries of Palinurus spp. Species of European waters: Palinurus elephas (Fabricius, 1787) and Palinurus mauritanicus (Gruvel, 1911). Cah Biol Mar 46:127-142

Goñi R, Reñones O, Quetglas A (2001) Dynamics of a protected Western Mediterranean population of the European spiny lobster Palinurus elephas (Fabricius, 1787) assessed by trap surveys. Mar Freshw Res 52:1577-1587

Goñi R, Quetglas A, Reñones O (2003a) Size at maturity, fecundity and reproductive potential of a protected population of the spiny lobster Palinurus elephas (Fabricius, 1787) from the Western Mediterranean. Mar Biol 143: 583-592

Goñi R, Quetglas A, Reñones O (2003b) Differential catchability of male and female European spiny lobster Palinurus elephas (Fabricius, 1787) in traps and trammel nets. Fish Res 65:295-307

Goñi R, Quetglas A, Reñones O (2006) Spillover of lobster Palinurus elephas (Fabricius 1787) from a Western Mediterranean marine reserve. Mar Ecol Prog Ser 308:207-219

Goñi R, Adlerstein S, Alvarez-Berastegui D, Forcada A and others (2008) Evidence of biomass export from six Western Mediterranean marine protected areas as measured from artisanal fisheries. Mar Ecol Prog Ser 366:159-174

Gristina M, Bahri T, Fiorentino F, Garofalo G (2006) Comparison of demersal fish assemblages in three areas of the Strait of Sicily under different trawling pressure. Fish Res 81:60-71

Guidetti P, Milazzo M, Bussottia S, Molinari A and others (2008) Italian marine reserve effectiveness: Does enforcement matter? Biol Conserv 141:699-709

Hall SJ (1999) The effects of fishing on marine ecosystems and communities. Blackwell Science, Oxford

> Halpern SH, Warner RR (2002) Marine reserves have rapid and lasting effects. Ecol Lett 5:361-366

- Harmelin JG, Bachet F, Garcia F (1995) Mediterranean marine reserves: fish indices as tests of protection efficiency. PSZN I: Mar Ecol 16:233-250

> Harmelin-Vivien M, Le Diréach L, Bayle-Sempere J, Charbonnel E and others (2008) Gradients of abundance and biomass across reserve boundaries in six Mediterranean marine protected areas: evidence of fish spillover? Biol Conserv 141:1829-1839

> Hurlbert SH (1984) Pseudoreplication and the design of ecological field experiments. Ecol Monogr 54:187-211

Jennings S, Kaiser MJ (1998) The effects of fishing on marine ecosystems. Adv Mar Biol 34:201-266 \& 268-352

Kaunda-Arara B, Rose GA (2004) Effects of marine reef National Parks on fishery CPUE in coastal Kenya. Biol Conserv 118:1-13

Kellner JB, Tetreault I, Gaines SD, Nisset RM (2007) Fishing the line near marine reserves in single and multispecies fisheries. Ecol Appl 17:1039-1054

Kleczkowski M, Babcock RC, Clapin G (2008) Density and size of fishes in and around a temperate marine reserve. Mar Freshw Res 59:165-176

Konstantinos IS, Vasiliki SK (2002) Feeding habits and trophic levels of Mediterranean fish. Rev Fish Biol Fish 11: $217-254$

Margalef R (1968) Perspectives in ecological theory. University of Chicago Press, Chicago, IL

Mas X, Goñi R, Fernandez JL (2004) Yields, bycatch and discards in the Mullus surmuletus gillnet fishery off southeastern Mallorca (Western Mediterranean). Rapp Comm Int Mer Médit 37:397

McClanahan TR, Mangi S (2000) Spillover of exploitable fishes from a marine park and its effect on the adjacent fishery. Ecol Appl 10:1792-1805

McClanahan TR, Graham NAJ, Calnan JM, MacNeil MA (2007) Toward pristine biomass: reef fish recovery in coral reef marine protected areas in Kenya. Ecol Appl 17: 1055-1067

Murawski SA (2000) Definitions of overfishing from an ecosystem perspective. ICES J Mar Sci 57:649-658

Ojeda-Martinez C, Bayle-Sempere J, Sánchez-Jerez P, Forcada A, Valle C (2007) Detecting conservation benefits in spatially protected fish populations with meta-analysis of long-term monitoring data. Mar Biol 151:1153-1161

> Piet GJ, Jennings S (2005) Response of potential fish community indicators to fishing. ICES J Mar Sci 62:214-225

Quetglas A, Gaamour O, Reñones H, Missaoui T, Zarrouk A, Elabed A, Goñi R (2004) Spiny lobster (Palinurus elephas Fabricius 1787) fishery in the western Mediterranean: a comparison of Spanish and Tunisian fisheries. Bol Soc Hist Nat Islas Baleares 47:63-80

Rakitin A, Kramer DL (1996) Effect of a marine reserve on the distribution of coral reef fishes in Barbados. Mar Ecol Prog Ser 131:97-113

Ramos-Esplá AA, Valle Perez C, Bayle Sempere JT, Sanchez Lizaso JL (2004) Áreas marinas protegidas como herramientas de gestión pesquera en el Mediterráneo (Area COPEMED). Serie Informes y Estudios COPEMED 11, FAO, Rome (www.faocopemed.org/vldocs/0001014)

Reñones O, Quetglas A, Goñi R (2001) Effects of fishing restrictions on the abundance, size structure and mortality rate of a western Mediterranean population of Scorpaena scrofa (Linnaeus, 1758). Rapp Comm Int Mer Médit 36:316

Roberts CM, Bohnsack JA, Gell F, Hawkins JP, Goodridge R (2001) Effects of marine reserves on adjacent fisheries. Science 294:1920-1923

Rochet MJ, Trenkel VM (2003) Which community indicators can measure the impact of fishing? A review and proposals. Can J Fish Aquat Sci 60:86-99

Russ GR (2002) Yet another review of marine reserves as reef fisheries management tools. In: Sale PF (ed) Coral reef fishes: dynamics and diversity in a complex ecosystem. Academic Press, San Diego, CA, p 421-443

Russ GR, Alcala AC (1996) Do marine reserves export adult fish biomass? Evidence from the Apo Island, central Philippines. Mar Ecol Prog Ser 132:1-9

Russ GR, Alcala AC (2004) Marine reserves: long-term protection is required for full recovery of predatory fish populations. Oecologia 138:622-627

Russ GR, Alcala AC, Maypa AP, Calumpong HP, White AT (2004) Marine reserves benefit local fisheries. Ecol Appl 14:597-606

> Russ GR, Stockwell B, Alcala AC (2005) Inferring versus measuring rates of recovery in no-take marine reserves. Mar Ecol Prog Ser 292:1-12

> Sánchez Lizaso JL, Goñi R, Reñones O, García-Chartón JA and others (2000) Density dependence in marine pro- 
tected populations: a review. Environ Conserv 27: $144-158$

Simpson EH (1949) Measurement of diversity. Nature 163:688

Stergiou KI, Moutopoulos DK, Soriguer MC, Puente E and others (2006) Trammel net catch species composition, catch rates and métiers in southern European waters: a multivariate approach. Fish Res 79:170-182

Tetreault I, Ambrose RF (2007) Temperate marine reserves enhance targeted but not untargeted fishes in multiple notake MPAs. Ecol Appl 17:2251-2267

Walters CJ, Christensen V, Pauly D (2002) Searching for optimum fishing strategies for fisheries development, recovery and sustainability. In: Pitcher TJ, Cochrane K (eds) The use of ecosystems models to investigate multispecies

Editorial responsibility: Tim McClanahan,

Mombasa, Kenya management strategies for capture fisheries. Fisheries Centre Research Report 10(2). University of British Columbia, Vancouver, p 11-15

Warwick RM, Clarke KR (1993) Increased variability as a symptom of stress in marine communities. J Exp Mar Biol Ecol 172:215-226

Warwick RM, Clarke KR (2001) Practical measures of marine biodiversity based on relatedness of species. Oceanogr Mar Biol Annu Rev 39:207-231

Warwick RM, Ashman CM, Brown AR, Clarke KR and others (2002) Inter-annual changes in the biodiversity and community structure of the macrobenthos in Tees Bay and the Tees estuary, UK, associated with local and regional environmental events. Mar Ecol Prog Ser 234:1-13

Submitted: April 22, 2008; Accepted: March 12, 2009

Proofs received from author(s): May 20, 2009 